\title{
Research \\ Characterization of tissue oxygen saturation and the vascular occlusion test: influence of measurement sites, probe sizes and deflation thresholds
}

\author{
Hernando Gómez ${ }^{1}$, Jaume Mesquida ${ }^{1}, 2$, Peter Simon ${ }^{1}$, Hyung Kook Kim ${ }^{1}$, Juan C Puyana ${ }^{3}$, \\ Can Ince ${ }^{4}$ and Michael R Pinsky ${ }^{1}$

\begin{abstract}
1'Department of Critical Care Medicine, University of Pittsburgh, 606 Scaife Hall, 3550 Terrace Street, Pittsburgh, PA 15261, USA
2Department of Medicine, Universitat Autònoma de Barcelona, Barcelona, 08193 Spain

3Department of Surgery, University of Pittsburgh, 200 Lothrop Street, Pittsburgh, PA 15213, USA

${ }^{4}$ Department of Intensive Care, Erasmus MC, University Medical Center Rotterdam, dr. Molewaterplein 40-60 3000 Dr Rotterdam, The Netherlands
\end{abstract}

Corresponding author: Michael R Pinsky, pinskymr@upmc.edu

Published: 30 November 2009

This article is online at http://ccforum.com/content/13/S5/S3

(c) 2009 BioMed Central Ltd
Critical Care 2009, 13(Suppl 5):S3 (doi:10.1186/cc8001)

Conclusion: $\mathrm{BaseO}_{2}, \mathrm{DeO}_{2}$ and $\mathrm{ReO}_{2}$ were different when measured in different anatomical sites $(\mathrm{F}$ and $\mathrm{TH})$ and with different probe sizes, and $\mathrm{ReO}_{2}$ was different with differing VOT release $\mathrm{StO}_{2}$ threshold values. Thus, standardization of the site, probe and VOT challenge need to be stipulated when reporting data.

occlusion test (VOT) can identify tissue hypoperfusion in trauma and sepsis. However, the technique is neither standardized nor uses the same monitoring site. We hypothesized that baseline and VOT $\mathrm{StO}_{2}$ would be different in the forearm (F) and thenar eminence $(\mathrm{TH})$ and that different minimal $\mathrm{StO}_{2}$ values during the VOT would result in different reoxygenation rates $\left(\mathrm{ReO}_{2}\right)$.

Methods: $\mathrm{StO}_{2}$ and its change during the VOT were simultaneously measured in the $\mathrm{F}$ and $\mathrm{TH}$, with $15 \mathrm{~mm}$ and $25 \mathrm{~mm}$ probes, using the $325 \mathrm{InSpectra}$ monitor in 18 healthy, adult volunteers. Two VOTs were done to a threshold thenar $\mathrm{StO}_{2}$ of $40 \%$ interchanging the $15 \mathrm{~mm}$ and $25 \mathrm{~mm}$ probes between sites. Two additional VOTs were done to thresholds of $50 \%$ and $30 \%$. Baseline $\mathrm{StO}_{2}\left(\mathrm{BaseO}_{2}\right)$, the deoxygenation rate $\left(\mathrm{DeO}_{2}\right)$ and $\mathrm{ReO}_{2}$ $\left(\% \mathrm{O}_{2} /\right.$ minute $)$ were compared between sites, probes and thresholds. Results are presented as the median (interquartile range), $P$-value.

Results: $\mathrm{BaseO}_{2}, \mathrm{DeO}_{2}, \mathrm{ReO}_{2}$, area under the curve and hyperemia duration values were different when comparing $\mathrm{TH}$ vs. $\mathrm{F}$ and $15 \mathrm{~mm}$ vs. $25 \mathrm{~mm}$ probes. $\mathrm{ReO}_{2}$ was different between different thresholds for the $\mathrm{TH}$ and $15 \mathrm{~mm}$ probes. $\mathrm{TH}_{15 \mathrm{~mm}}$ vs. $\mathrm{F}_{15 \mathrm{~mm}}: \mathrm{BaseO}_{2}, 90.4(85.2,93.5)$ vs. $85.2(80.7,90.2), P=0.031$; $\mathrm{DO}_{2},-12.1(-16.2,-11.3)$ vs. $-8.5(-10.3,-7.8), P=0.011$; $\mathrm{ReO}_{2}, 297.2$ (213.7, 328.6), $P<0.0001 ; 15 \mathrm{~mm}$ vs. $25 \mathrm{~mm}$ probe: $\mathrm{BaseO}_{2}, 97.2(89.4,94.7)$ vs. $87.3(81.7,90.9), P=0.016 ; \mathrm{DeO}_{2}$, $-18.0(-24.1,-14.8)$ vs. $-9.9(-15.3,-6.5), P<0.0001$; and $\mathrm{ReO}_{2}, 401.6(331.7,543.2)$ vs. 160.5 (132.3, 366.9), $P=0.012$, respectively. $\mathrm{TH}_{15 \mathrm{~mm}}$ vs. $\mathrm{TH}_{25 \mathrm{~mm}}: \mathrm{BaseO}_{2}, P=0.020 ; \mathrm{DeO}_{2}$, $P<0.0001$; and $\mathrm{ReO}_{2}, P<0.0001$. Threshold $\mathrm{StO}_{2}$ values $(15 \mathrm{~mm}$ probe only): $\mathrm{ReO}_{2}, P=0.003 ; \mathrm{DeO}_{2}, P=0.60$. $\mathrm{ReO}_{2}$ at $40 \%$ and $50 \% \mathrm{StO}_{2}$ thresholds, $P=0.01$.

\section{Introduction}

Non-invasive measurements of tissue oxygen saturation $\left(\mathrm{StO}_{2}\right)$ using near-infrared spectroscopy have been studied to assess tissue hypoperfusion in different populations. The absolute $\mathrm{StO}_{2}$ has been proven instrumental in predicting outcome in trauma patients [1,2]. These same studies, however, have shown limited discriminating capacity for the absolute $\mathrm{StO}_{2}$ value (sensitivity, 78\%; specificity, 39\%) and have even shown it to be at least as good as systolic blood pressure (sensitivity, 74\%; specificity, 32\%) [1]. The addition of a provocative test (ischaemic challenge) to the measurement of the $\mathrm{StO}_{2}$ would potentially enhance this discriminatory power between different cardiovascular states by creating emerging parameters to follow, such as the deoxygenation and reoxygenation slopes. Furthermore, the use of such provocative tests [3], specifically the vascular occlusion test (VOT), has been shown to improve and expand the predictive ability of $\mathrm{StO}_{2}$ to scenarios such as trauma, severe sepsis and septic shock $[4,5]$.

The VOT is a provocative test in which $\mathrm{StO}_{2}$ is measured on a distal site (such as the thenar eminence (TH)) whilst a transient rapid vascular occlusion is performed, using a sphygmomanometer, for either a defined time interval (for

$\mathrm{BaseO}_{2}=$ baseline tissue oxygen saturation; $\mathrm{DeO}_{2}=$ deoxygenation rate; $\mathrm{F}=$ forearm; $\mathrm{ReO}_{2}=$ reoxygenation rate; StO $\mathrm{O}_{2}=$ tissue oxygen saturation; $\mathrm{TH}=$ thenar eminence; VOT $=$ vascular occlusion test. 
example, 3 minutes) or until the $\mathrm{StO}_{2}$ decreases to a defined minimal threshold. Once this threshold is reached, the vascular occlusion is released and the $\mathrm{StO}_{2}$ is allowed to recover. Several emergent parameters arise from this technique, including the rate of deoxygenation $\left(\mathrm{DeO}_{2}\right)$, thought to reflect the local metabolic rate, the rate of reoxygenation $\left(\mathrm{ReO}_{2}\right)$, which reflects the time required to wash out stagnant blood and is thought to be determined by local cardiovascular reserve and microcirculatory flow, and the postobstructive hyperemic response.

The VOT, however, has not been standardized. In fact, multiple studies report results using different anatomical $\mathrm{StO}_{2}$ measuring sites ( $\mathrm{TH}$, forearm $(\mathrm{F})$, deltoid) [4,6-8], different near-infrared spectroscopy probe sizes ( $15 \mathrm{~mm}$ vs. $25 \mathrm{~mm}$ ) [4,8-12], and different types and levels of deflation thresholds $\left(\mathrm{StO}_{2}\right.$ of $40 \%$, $50 \%$ ) versus time thresholds (3 minutes, 4 minutes, 5 minutes) $[4,6,11,13]$. Differences between anatomical sites may potentially affect near-infrared spectroscopy-derived parameters given the fact that fat and the muscle thickness distribution along the body is variable. Furthermore, given that increasing the sensing and illuminating probe distance augments the depth that near-infrared light travels, the use of different probes may screen different capillary beds at any given time. Finally, since the primary reason to perform the VOT is to produce a transient ischaemic challenge to note the subsequent $\mathrm{ReO}_{2}$, the level of ischaemic challenge might vary for the same ischaemic time or threshold $\mathrm{StO}_{2}$. As a consequence, caution must be taken when comparing results from the available literature on the VOT, as the test may be inadequate $[14,15]$.

We hypothesized that absolute $\mathrm{StO}_{2}$ values and VOT-derived $\mathrm{StO}_{2}$ values obtained by monitoring different anatomical sites or using dissimilar depth may differ, and that different minimal $\mathrm{StO}_{2}$ values during the VOT (deflation thresholds) would result in dissimilar $\mathrm{ReO}_{2}$ rates.

\section{Materials and methods}

The present study was approved by the Institutional Review Board of the University of Pittsburgh. Informed consent was obtained from every volunteer enrolled in the study prior to performing any procedure.

\section{Near-infrared spectroscopy}

$\mathrm{StO}_{2}$ and its change during the VOT were simultaneously measured in the $\mathrm{F}$ and $\mathrm{TH}$, with $15 \mathrm{~mm}$ and $25 \mathrm{~mm}$ probes, using two 325 InSpectra ${ }^{\circledR}$ tissue spectrometers (Hutchinson Technology Inc., Minneapolis, MN, USA) on the same arm in 18 healthy, adult volunteers. Placement of the $\mathrm{TH}$ probe was done according to the manufacturer's recommendations as previously described $[4,9]$. The F probe was placed over the Flexor digitorum profundus in the $\mathrm{F}$.

Research software (InSpectra Version vBeta1.1; Hutchinson Technology Inc.) on two independent laptop computers was used for data collection.
Figure 1

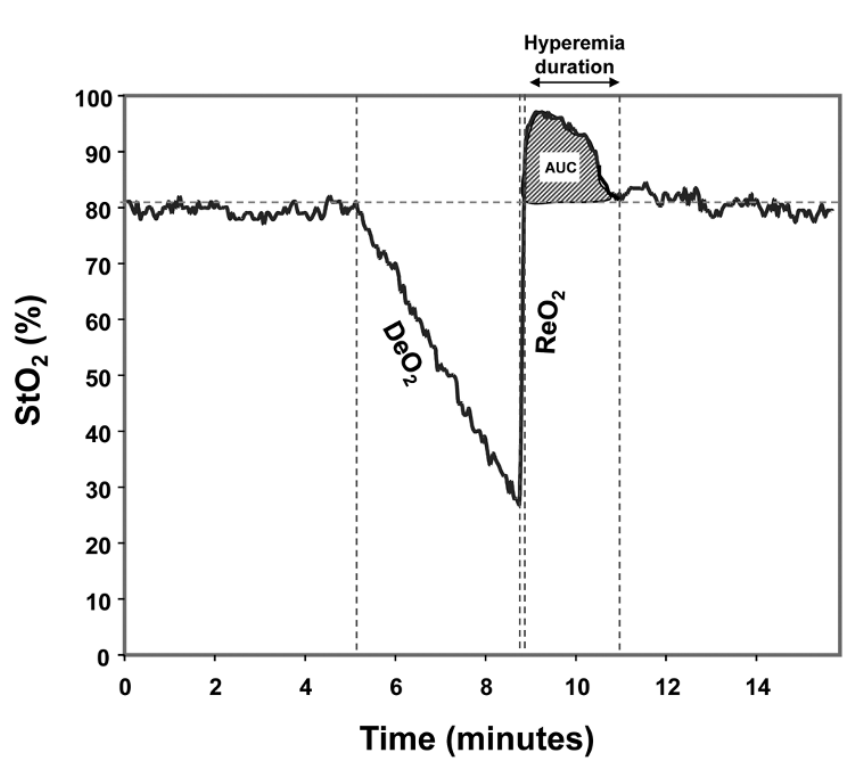

Tissue oxygen saturation $\left(\mathrm{StO}_{2}\right)$ during a vascular occlusion test. Calculated parameters: deoxygenation rate $\left(\mathrm{DeO}_{2}\right)$, reoxygenation rate $\left(\mathrm{ReO}_{2}\right)$, hyperemia area under the curve (AUC), and hyperemia duration.

\section{Vascular occlusion test}

The VOT was performed as previously described [9]. Briefly, the baseline arterial pressure was measured using a manual sphygmomanometer. An adult-size tourniquet cuff was then placed on the arm above both probes. After $\mathrm{StO}_{2}$ signal stabilization at rest $(<2 \%$ variation in 30 seconds), the tourniquet was inflated with an automatic pump (Portable Tourniquet System, ref. 9-2100-001; Delfi Medical Innovations Inc., Vancouver, BC, Canada) to $>30 \mathrm{mmHg}$ above systolic pressure and was kept inflated until the $\mathrm{StO}_{2}$ decreased to $40 \%$ (deflation threshold). Inflation took approximately 3 to 4 seconds. The tourniquet was then rapidly deflated $(<0.5$ seconds $)$ and the $\mathrm{StO}_{2}$ response was followed until the $\mathrm{StO}_{2}$ returned to baseline values. All repeated VOTs were performed after a minimal period of 5 minutes to allow the $\mathrm{StO}_{2}$ to recover.

$\mathrm{DeO}_{2}$ and $\mathrm{ReO}_{2}$ slopes, the area under the curve of the hyperemic response as well as the duration of hyperemia (Figure 1) were calculated using the published methodology and a software package designed for this purpose and this specific tissue spectrometer (Version 3.03 InSpectra Analysis Program; Hutchinson Technology Inc.), as previously validated by us [9].

\section{Protocol}

Subjects were placed in a quiet environment while resting in a semirecumbent position with the studied arm resting over a cushion in the anatomical position. Probes were placed using a form-fitting plastic adhesive over the $\mathrm{TH}$ and volar surface 
of the $F$. The $15 \mathrm{~mm}$ probe was initially placed on the $F$ and the $25 \mathrm{~mm}$ probe placed on the TH. A VOT was then performed. After a 5-minute resting period, the probe locations were switched (that is, the $15 \mathrm{~mm}$ probe to the $\mathrm{TH}$, and the $25 \mathrm{~mm}$ probe to the F) and a second VOT was performed. Subsequently, two additional VOTs were carried out to $\mathrm{StO}_{2}$ deflation thresholds of $50 \%$ and $30 \%$ with the same probe disposition.

\section{Healthy volunteers}

Volunteers were selected according to the following inclusion and exclusion criteria: inclusion criterion, subjects older than 17 years (that is, $\geq 18$ years); and exclusion criteria, acute or chronic cardiovascular or pulmonary disease, or subject taking any vasoactive medications.

\section{Statistical analysis}

Mean absolute $\mathrm{StO}_{2}$ values, the $\mathrm{DeO}_{2}$ and the $\mathrm{ReO}_{2}$ $\left(\% \mathrm{O}_{2} /\right.$ minute $)$ as measured by the $15 \mathrm{~mm}$ and $25 \mathrm{~mm}$ probes between the $\mathrm{TH}$ and $\mathrm{F}$ monitoring sites were compared using the Wilcoxon signed-ranks test. Comparison of the $\mathrm{DeO}_{2}$ and $\mathrm{ReO}_{2}$ when the VOT was performed at different $\mathrm{StO}_{2}$ deflation thresholds (that is, $\mathrm{StO}_{2}$ of $30 \%, 40 \%$ and $50 \%$ ) was performed using the Friedman test and analysis of variance for repeated measures (after running normality tests). Results are presented as the median (interquartile range), $P$-value unless stated otherwise. Significance reports a difference between groups corresponding to $P<0.05$ unless stated otherwise.

\section{Results}

Eighteen healthy volunteers were enrolled in the present study after obtaining informed consent. Demographic characteristics of the studied population are summarized in Table 1. The mean baseline $\mathrm{StO}_{2}, \mathrm{DeO}_{2}, \mathrm{ReO}_{2}$ and their coefficients of variability for these measures for the various comparisons are summarized in Table 2.

The absolute $\mathrm{StO}_{2}, \mathrm{DeO}_{2}$ and $\mathrm{ReO}_{2}$ values for a deflation threshold of $40 \%$ were different between the $\mathrm{TH}$ and $\mathrm{F}$ for both the $15 \mathrm{~mm}$ and $25 \mathrm{~mm}$ probes (Figures 2 and 3), and were also different at the TH site for the $15 \mathrm{~mm}$ and $25 \mathrm{~mm}$ probes (Figure 4). Not surprisingly, the $\mathrm{TH} \mathrm{DeO}_{2}$ was not altered by varying the deflation $\mathrm{StO}_{2}$ thresholds from $30 \%$ to $50 \%$ when measured with the $15 \mathrm{~mm}$ probe. This result was expected given that the $\mathrm{DeO}_{2}$ is dependent on the metabolic conditions of the tissue, independent of the intensity of the ischemic insult and given the specific calculation methodology [1]. If the metabolic rate of the sampled tissue was not varied, therefore, the $\mathrm{DeO}_{2}$ should not be significantly modified. The $\mathrm{ReO}_{2}$ was higher using the 30\% threshold than either the $40 \%$ or $50 \%$ thresholds, which themselves were similar (Figure 5).

The coefficients of variability for the absolute $\mathrm{StO}_{2}, \mathrm{DeO}_{2}$ and $\mathrm{ReO}_{2}$ values were also different when comparing both sites
Table 1

\begin{tabular}{lc}
\multicolumn{2}{l}{ Demographic characteristics of the study population } \\
\hline Characteristic & Value \\
\hline Age (years) & $32.9 \pm 8.2$ \\
Gender & $6(33 \%)$ \\
$\quad$ Female & $12(67 \%)$ \\
$\quad$ Male & \\
Race & $10(56 \%)$ \\
$\quad$ Caucasian & $4(22 \%)$ \\
$\quad$ Hispanic & $3(17 \%)$ \\
$\quad$ Asian & $1(5 \%)$ \\
$\quad$ Indian & $75.5 \pm 15.5$ \\
Weight (kg) & $175.8 \pm 8.2$ \\
Height (cm) & $36.1 \pm 0.6$ \\
Temperature $\left({ }^{\circ} \mathrm{C}\right)$ & $118 \pm 12$ \\
Systolic blood pressure $(\mathrm{mmHg})$ & $73 \pm 7$ \\
Diastolic blood pressure $(\mathrm{mmHg})$ & $88 \pm 8$ \\
Mean arterial pressure $(\mathrm{mmHg})$ & $69 \pm 9$ \\
Heart rate (beats/minute) & \\
\hline Data & \\
\hline
\end{tabular}

Data are presented as mean \pm standard deviation or $n(\%)$.

and probes, being less with the $\mathrm{TH}$ than $\mathrm{F}$ measures and with the $15 \mathrm{~mm}$ than $25 \mathrm{~mm}$ probe size. We also observed a lower coefficient of variability with $40 \%$ and $50 \%$ thresholds as compared with the $30 \%$ threshold (Table 3).

The mean \pm standard deviation hyperemic areas under the curve (Figure 1) as measured by $\mathrm{TH}_{15 \mathrm{~mm}}, \mathrm{TH}_{25 \mathrm{~mm}}, \mathrm{~F}_{15 \mathrm{~mm}}$ and $\mathrm{F}_{25 \mathrm{~mm}}$ were $11.2 \pm 8.8 \% \mathrm{O}_{2} /$ minute, $7.7 \pm 5.1 \% \mathrm{O}_{2} /$ minute, $6.4 \pm 5.7 \% \mathrm{O}_{2} /$ minute and $13.2 \pm 9.6 \% \mathrm{O}_{2} /$ minute, respectively, and were all significantly different when compared among each other (Figure 6). Their coefficients of variability were $78.7 \%, 66.2 \%, 90.3 \%$ and $72.5 \%$, respectively. The hyperemia durations (mean \pm standard deviation) for the same measurements stated above were $2.3 \pm 0.8$ minutes, $1.8 \pm 0.6$ minutes, $1.6 \pm 0.5$ minutes and $2.8 \pm 1.2$ minutes, respectively. These were also statistically different from each other, as shown in Figure 6. Their coefficients of variability were $32.9 \%, 33.5 \%, 34.1 \%$ and $33.5 \%$, respectively.

\section{Discussion}

Baseline $\mathrm{StO}_{2}$ values and their emergent parameters of the $\mathrm{DeO}_{2}$ and the $\mathrm{ReO}_{2}$, assessed by the VOT, are dependent on the site of measurement, the probe size and, to a certain extent, the ischaemic challenge. Varying any one of these components will significantly vary $\mathrm{StO}_{2}$-related measures independent of the baseline cardiovascular status. When making inferences about cardiovascular function using these measures, therefore, care must be taken in comparing or 
Table 2

Baseline tissue oxygen saturation, deoxygenation and reoxygenation rates between sites and between probe sizes

\begin{tabular}{lcccc}
\hline Probe & $\begin{array}{c}\text { Thenar } \\
\text { eminence }\end{array}$ & $\begin{array}{c}\text { Coefficient of } \\
\text { variability (\%) }\end{array}$ & Forearm & $\begin{array}{c}\text { Coefficient of } \\
\text { variability (\%) }\end{array}$ \\
\hline $15 \mathrm{~mm}$ value
\end{tabular}

Baseline tissue oxygen saturation $\left(\mathrm{StO}_{2}\right)$, deoxygenation rate $\left(\mathrm{DeO}_{2}\right)$ and reoxygenation rate $\left(\mathrm{ReO}_{2}\right)$ between the thenar eminence versus forearm and between the $15 \mathrm{~mm}$ probe versus $25 \mathrm{~mm}$ probe. Data presented as the median (interquartile range). aThenar eminence versus forearm comparison. bAbsolute $\mathrm{StO}_{2}$ range.

\section{Figure 2}

\section{$\mathrm{TH}_{15 \mathrm{~mm}}$ vs. $\mathrm{F}_{15 \mathrm{~mm}}$}
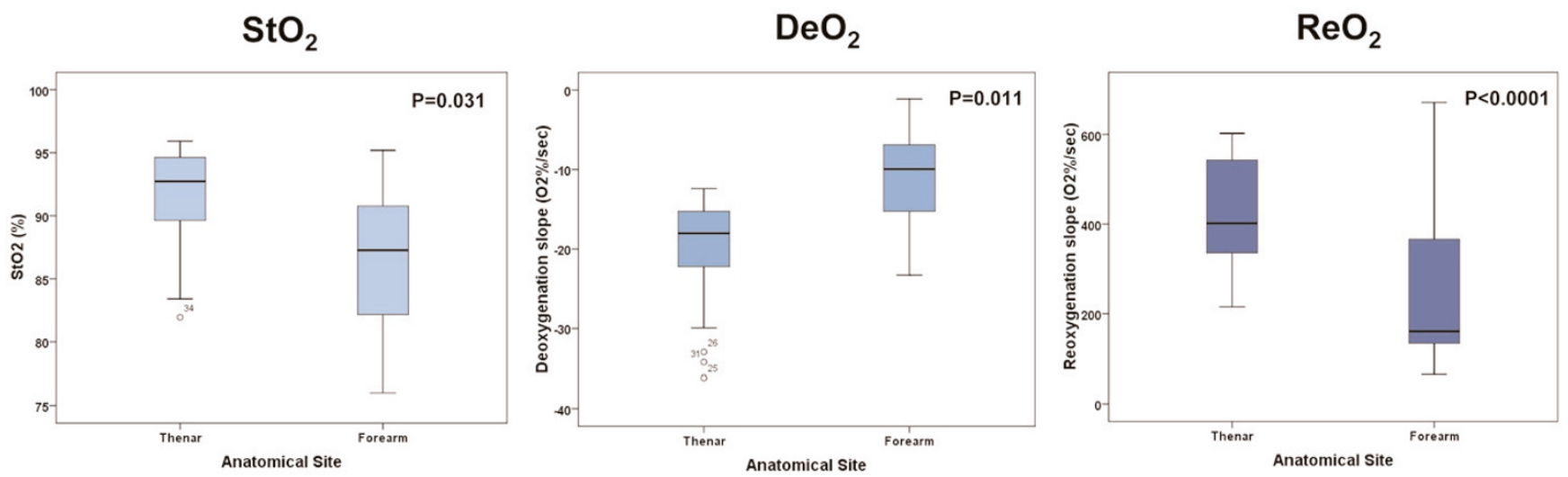

Box plots comparing tissue oxygen saturation $\left(\mathrm{StO}_{2}\right)$ parameters measured with the $15 \mathrm{~mm}$ probe at different anatomical sites. DeO deoxygenation rate; $\mathrm{ReO}_{2}$, reoxygenation rate.

combining results from different studies that use different measurement techniques and protocols. Presently, the VOT ischaemic challenge has not been standardized. Several investigators report the $\mathrm{DeO}_{2}$ and the $\mathrm{ReO}_{2}$ from a fixed ischaemic time (for example, 3 minutes) rather than to a defined threshold $\mathrm{StO}_{2}$ value. Since the basal metabolic rate can vary amongst subjects, varying the $\mathrm{DeO}_{2}$ proportionally
[3] using a fixed ischaemic time will result in differing threshold $\mathrm{StO}_{2}$ values within and among subjects, making changes in the $\mathrm{ReO}_{2}$ difficult to interpret among subjects if their metabolic rates are also different because they will reach different $\mathrm{StO}_{2}$ nadirs for a constant ischaemic time. Our data therefore support using a defined ischaemic $\mathrm{StO}_{2}$ threshold in future studies to minimize $\mathrm{ReO}_{2}$ variability. 


\section{$\mathrm{TH}_{25 \mathrm{~mm}}$ vS. $\mathbf{F}_{25 \mathrm{~mm}}$}

\section{$\mathrm{StO}_{2}$}

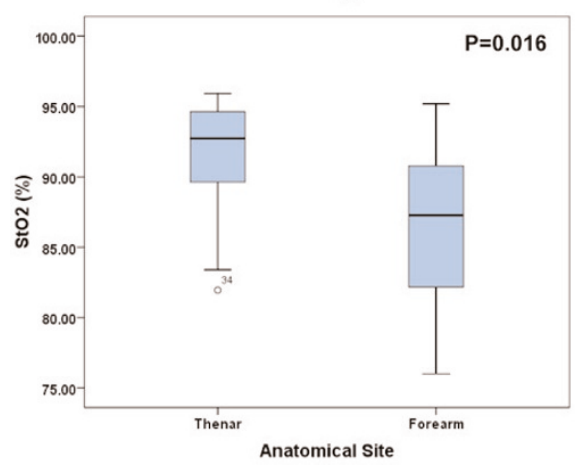

$\mathrm{DeO}_{2}$

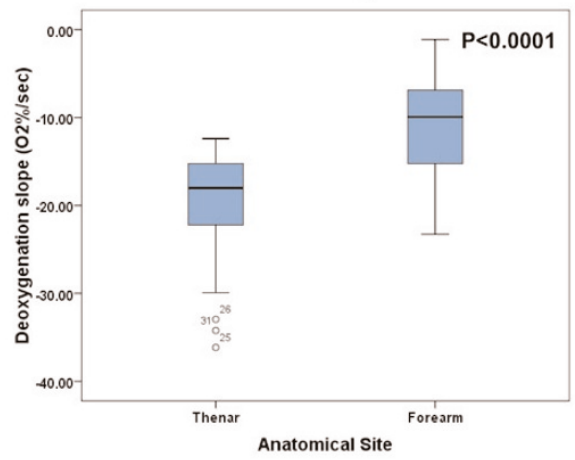

$\mathrm{ReO}_{2}$

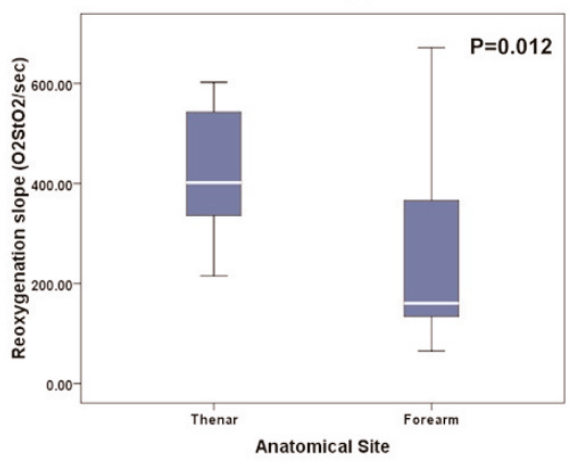

Box plots comparing tissue oxygen saturation $\left(\mathrm{StO}_{2}\right)$ parameters measured with the $25 \mathrm{~mm}$ probe at different anatomical sites. DeO deoxygenation rate; $\mathrm{ReO}_{2}$, reoxygenation rate.

\section{$\mathrm{TH}_{15 \mathrm{~mm}}$ vs. $\mathrm{TH}_{25 \mathrm{~mm}}$}
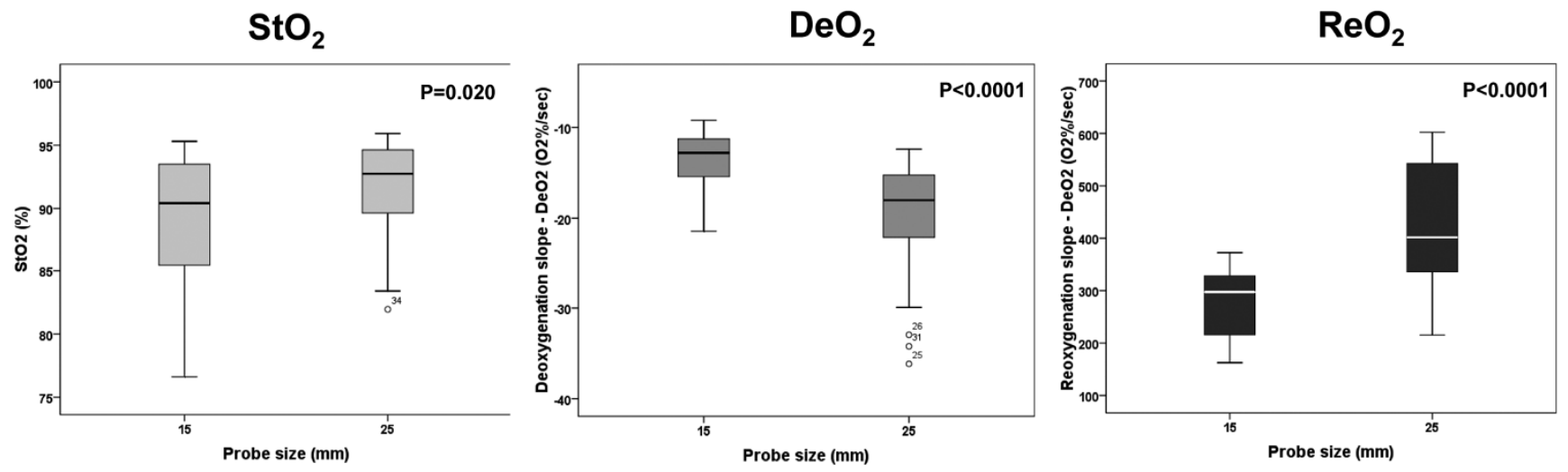

Box plots comparing tissue oxygen saturation $\left(\mathrm{StO}_{2}\right)$ parameters measured on the thenar eminence with different probes. DeO $\mathrm{O}_{2}$, deoxygenation rate; $\mathrm{ReO}_{2}$, reoxygenation rate.

We found that the baseline $\mathrm{StO}_{2}, \mathrm{DeO}_{2}$ and $\mathrm{ReO}_{2}$ values were consistently higher in the $\mathrm{TH}$ than $\mathrm{F}$ sites. Furthermore, the magnitude of the difference between the $\mathrm{TH}$ and $\mathrm{F}$ was greater for $\mathrm{DeO}_{2}$ and $\mathrm{ReO}_{2}$ values than for baseline $\mathrm{StO}_{2}$ values. There was also a trend toward a greater variability for baseline $\mathrm{StO}_{2}$ at $\mathrm{F}$ than at $\mathrm{TH}$ sites. This variability was increased for the $\mathrm{DeO}_{2}$ and $\mathrm{ReO}_{2}$. Although our study does not allow us to identify why this difference occurs, most probably it reflects the greater degree of tissue and the associated vascular variability present in the $\mathrm{F}$ over the $\mathrm{TH}$. The $F$ has a variable layer of subcutaneous fat, which has a lower metabolic rate and minimal microcirculatory density when compared with muscle. The $\mathrm{TH}$ has almost no fat and is highly consistent amongst subjects. Our data therefore support using the $\mathrm{TH}$ site rather then the $\mathrm{F}$ site when measuring $\mathrm{StO}_{2}$ and its VOT-related parameters. 


\section{$\mathrm{StO}_{2}$ deflation thresholds $30 \%$ vs. $40 \%$ vs. $50 \%$}
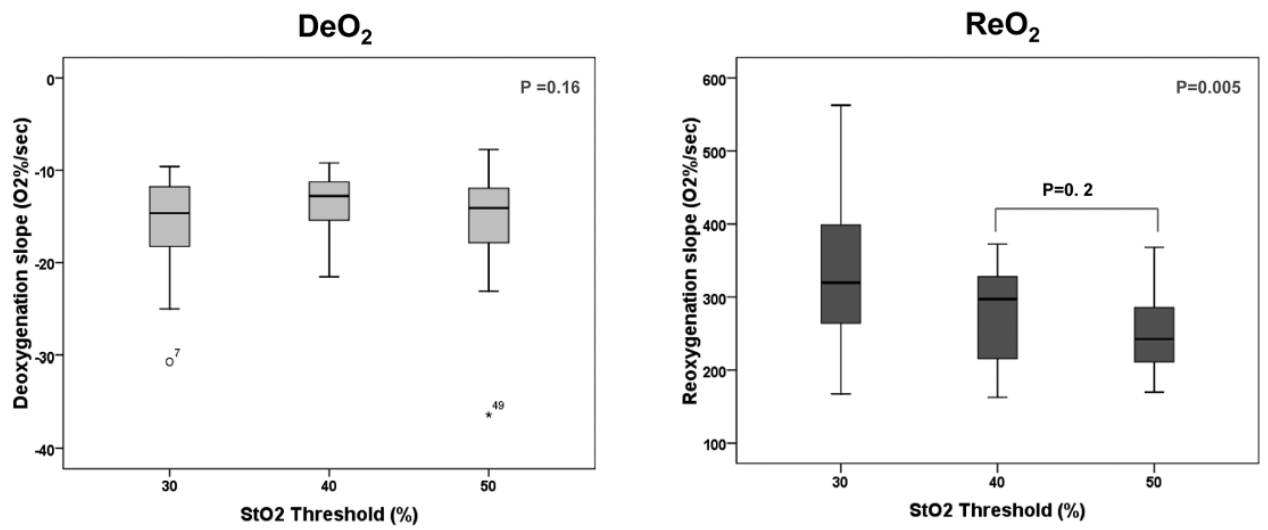

Box plots comparing $\mathrm{StO}_{2}$ parameters measured using different deflation thresholds. $\mathrm{DeO}_{2}$, deoxygenation rate; $\mathrm{ReO}$, reoxygenation rate.

Table 3

Deoxygenation rate and reoxygenation rate when using different deflation thresholds

\begin{tabular}{|c|c|c|c|c|}
\hline \multirow[b]{2}{*}{ Vascular occlusion test parameter } & \multicolumn{3}{|c|}{ Tissue oxygen saturation deflation threshold } & \multirow[b]{2}{*}{$P$-value } \\
\hline & $30 \%$ & $40 \%$ & $50 \%$ & \\
\hline $\mathrm{DeO}_{2}\left(\% \mathrm{O}_{2} /\right.$ minute $)$ & $-14.6(-18.5,-11.6)$ & $-12.8(-16.2,-11.3)$ & $-14.1(-18.0,-11.9)$ & 0.6 \\
\hline $\mathrm{ReO}_{2}\left(\% \mathrm{O}_{2} /\right.$ minute $)$ & $319.7(258.2,401.5)$ & $297.2(213.7,328.6)^{a}$ & $242.5(211.1,296.2)^{a}$ & 0.01 \\
\hline Coefficient of variability for $\mathrm{DeO}_{2}(\%)$ & 34.4 & 26.1 & 39.3 & \\
\hline Coefficient of variability for $\mathrm{ReO}_{2}(\%)$ & 30.1 & 21.5 & 21.0 & \\
\hline
\end{tabular}

Data are presented as the median (interquartile range). $\mathrm{DeO}_{2}$, deoxygenation rate; $\mathrm{ReO}_{2}$, reoxygenation rate. ${ }^{\mathrm{a} C o m p a r i s o n}$ of $\mathrm{ReO}{ }_{2}$ obtained using deflation thresholds of $40 \%$ and $50 \%$ was not significant $(P=0.2)$.

We also found consistently lower baseline $\mathrm{StO}_{2}$ values with the $15 \mathrm{~mm}$ probe than with the $25 \mathrm{~mm}$ probe, and this difference increased with VOT-related parameters. Although baseline $\mathrm{StO}_{2}$ values displayed a similar variability (5.6\% vs. $4.6 \%$ ), VOT-derived measurements performed with the $15 \mathrm{~mm}$ probe showed less variability than those performed with the $25 \mathrm{~mm}$ probe. Presumably, by sampling a smaller amount of tissue volume, the $15 \mathrm{~mm}$ probe is less subject to measurement error. Our data support the routine use of the $15 \mathrm{~mm}$ probe over the $25 \mathrm{~mm}$ probe in future studies.

The hyperemic response, as quantified by the area under the curve and the duration, varied according to the anatomical site of measurement and the probe size used. Furthermore, great variability was found among healthy volunteers with regards to both parameters, as previously pointed out by our group [9]. These results suggest that the hyperemic response is not a reproducible parameter, and has been proven to be highly dependent on individual variability. Thus, it may not be a reliable parameter for clinical use.

\section{Limitations}

The present study has two primary limitations.

First, we studied only two anatomical sites, whereas $\mathrm{StO}_{2}$ can be measured anywhere on the body. Extrapolation of these findings to other anatomical sites, such as the abdominal wall, thigh and masseter muscles, should be done with caution. Since the VOT can only be carried out realistically on a peripheral site for which transient ischaemia will have no lasting deleterious effects, however, these studies reflect the present clinical practice of near-infrared spectroscopy VOT analysis.

Second, we did not study critically ill patients but healthy volunteers. Although this was the goal of the study, its application to critically ill patients might be limited. Previous 

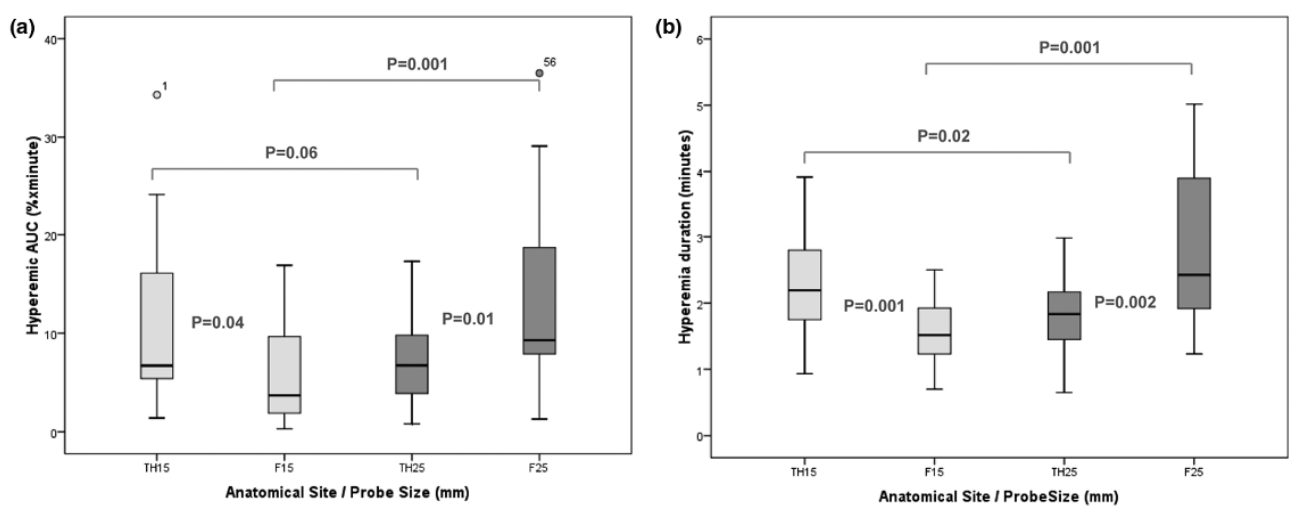

Box plot comparison of the hyperemic response between anatomical sites and probe sizes. AUC, hyperemic area under the curve.

studies by ourselves and others document that cardiovascular insufficiency can markedly increase intersubject variability $[4,9]$. Our data demonstrated a consistently lower coefficient of variation whenever the combination of $\mathrm{TH}$ site and $15 \mathrm{~mm}$ probe was used, which suggests that this site may also yield more consistent data in clinical trials. Similarly, using a defined ischaemic threshold for the VOT, methodspecific variability of the $\mathrm{ReO}_{2}$ should also be minimized.

\section{Competing interests}

$H G, J M$ and HKK are co-investigators in a Hutchinsonsponsored clinical trial. $\mathrm{Cl}$ has received honorarium for speaking at a Hutchinson Symposium, and is a coinvestigator on a Hutchinson-sponsored clinical trial. MRP and JCP have received an honorarium for speaking at a Hutchinson Symposium, and are co-investigators on a Hutchinson-sponsored prospective clinical trial. PS declares that he has no competing interests.

\section{Acknowledgements}

The authors want to thank the Department of Critical Care Medicine of the University of Pittsburgh, especially Dr Erick Itoman, Chief Fellow of the Multidisciplinary Critical Care Fellowship. They also want to thank Dr Alvaro Sanchez-Ortiz, MD, MPH for his contribution to the statistical analysis for the present paper. The present research was supported in part by NHLBI grants HL67181 and HL76157.

This article is part of Critical Care Volume 13 Supplement 5: Tissue oxygenation $\left(\mathrm{StO}_{2}\right)$ in healthy volunteers and critically-ill patients. The full contents of the supplement are available online at http://ccforum. $\mathrm{com} /$ supplements/13/S5. Publication of the supplement has been supported with funding from Hutchinson Technology Inc.

\section{References}

1. Cohn SM, Nathens AB, Moore FA, Rhee P, Puyana JC, Moore EE, Beilman GJ: Tissue oxygen saturation predicts the development of organ dysfunction during traumatic shock resuscitation. J Trauma 2007, 62:44-54; discussion 54-55.

2. Crookes BA, Cohn SM, Bloch S, Amortegui J, Manning R, Li P Proctor MS, Hallal A, Blackbourne LH, Benjamin R, Soffer D, Habib F, Schulman Cl, Duncan R, Proctor KG: Can near-infrared spectroscopy identify the severity of shock in trauma patients? J Trauma 2005, 58:806-813; discussion 813-816.

3. Convertino VA, Ryan KL, Rickards CA, Salinas J, McManus JG,
Cooke WH, Holcomb JB: Physiological and medical monitoring for en route care of combat casualties. J Trauma 2008, 64(4 Suppl):S342-S353.

4. Creteur J, Carollo T, Soldati G, Buchele G, De Backer D, Vincent $\mathrm{JL}$ : The prognostic value of muscle $\mathrm{StO}_{2}$ in septic patients. Intensive Care Med 2007, 33:1549-1556.

5. Gomez H, Torres A, Polanco P, Kim H, Zenker S, Puyana J, Pinsky $\mathrm{M}$ : Use of non-invasive NIRS during a vascular occlusion test to assess dynamic tissue $\mathrm{O}_{2}$ saturation response. Intensive Care Med 2008, 34:1600-1607.

6. De Blasi RA, Quaglia E, Gasparetto A, Ferrari M: Muscle oxygenation by fast near infrared spectrophotometry (NIRS) in ischemic forearm. Adv Exp Med Biol 1992, 316:163-172.

7. Podbregar M, Mozina $\mathrm{H}$ : Skeletal muscle oxygen saturation does not estimate mixed venous oxygen saturation in patients with severe left heart failure and additional severe sepsis or septic shock. Crit Care 2007, 11:R6.

8. Soller BR, Ryan KL, Rickards CA, Cooke WH, Yang Y, Soyemi $\mathrm{OO}$, Crookes BA, Heard SO, Convertino VA: Oxygen saturation determined from deep muscle, not thenar tissue, is an early indicator of central hypovolemia in humans. Crit Care Med 2008, 36:176-182.

9. Gomez H, Torres A, Polanco P, Kim HK, Zenker S, Puyana JC, Pinsky MR: Use of non-invasive NIRS during a vascular occlusion test to assess dynamic tissue $\mathrm{O}_{2}$ saturation response. Intensive Care Med 2008, 34:1600-1607.

10. Siafaka A, Angelopoulos E, Kritikos K, Poriazi M, Basios N, Gerovasili V, Andreou A, Roussos C, Nanas S: Acute effects of smoking on skeletal muscle microcirculation monitored by near-infrared spectroscopy. Chest 2007, 131:1479-1485.

11. Skarda DE, Mulier KE, Myers DE, Taylor JH, Beilman GJ: Dynamic near-infrared spectroscopy measurements in patients with severe sepsis. Shock 2007, 27:348-353.

12. Yang Y, Soyemi O, Scott PJ, Landry MR, Lee SM, Stroud L, Soller $B$ : Quantitative measurement of muscle oxygen saturation without influence from skin and fat using continuous-wave near infrared spectroscopy. Opt Express 2007, 15:13715-13730.

13. De Blasi RA, Cope M, Elwell C, Safoue F, Ferrari M: Noninvasive measurement of human forearm oxygen consumption by near infrared spectroscopy. Eur J Appl Physiol Occup Physiol 1993, 67:20-25.

14. Creteur J: Muscle $\mathrm{StO}_{2}$ in critically ill patients. Curr Opin Crit Care 2008, 14:361-366.

15. Ince C, Bezemer R, Lima A: Letters to the editor: Near infrared spectroscopy. Crit Care Med 2009, 37:384-385. 